\title{
If we redesigned copyright from scratch, what might it look like?
}

\section{Rebecca Giblin and Kimberlee Weatherall}

What if we could start with a blank slate, and write ourselves a brand new copyright system? If we could scrap the existing structure entirely and design a law to encourage creativity, remunerate and support creators, and increase the size of cultural markets to ensure broad access to new knowledge and creativity; in short, if we could draw up a new copyright law that genuinely furthered the public interest, what might it look like? Would we opt for radical overhaul? Or would we keep our current fundamentals? What parts of the system would we jettison? What would we keep?

Most critical and academic commentary on copyright takes current law as a given. ${ }^{1}$ Not uncommonly, commentators lament the way that the current copyright system was conceived in very different technological and economic conditions, and built on foundations that

1 This is true even of projects that aim to rethink the copyright system: e.g. Jessica Litman, Digital Copyright (Prometheus Books, $2^{\text {nd }}$ ed, 2006); Pamela Samuelson, 'The Copyright Principles Project' (2010) 25 Berkeley Technology Law Journal 1175. The explicit goal of the Copyright Principles project was to 'improve' and 'refine' copyright law by seeking to explore the level of possible 'consensus': Samuelson at 1175, 1176. Another project along similar lines was the Wittem Project, which aimed to develop a model copyright law designed to operate within the international obligations of the European Union (and thus be consistent with both the Berne Convention and TRIPS (Berne Convention for the Protection of Literary and Artistic Works, opened for signature 9 September 1886 (amended in 1914, 1928, 1948, 1967, 1971, and 1979) 25 UST 1341, 828 UNTS 221, entered into force 5 December 1887; and Marrakesh Agreement Establishing 
have been undermined by technological, economic and social change. Much has changed in the decades since copyright's foundational frameworks were settled. Perhaps most fundamental is the way in which the advent of digital technologies has driven the marginal cost of distributing many kinds of cultural and informational work towards zero, which, at least in some senses and for some people, has eliminated scarcity. ${ }^{2}$ At the same time, we have also come to know more than ever before about how the theory of how copyright was supposed to work actually matches up with practice. ${ }^{3}$

But treaty obligations, political realities and existing economic interests and business models all combine to lock in the status quo. And so most discussion of possible copyright reform is pragmatic, and tinkers at the margins: it aims for achievable change within the confines of the existing international frameworks.

This collection does something bolder. Contributors were asked to apply these new realities and knowledge advances to key areas of copyright policy: to imagine what copyright law might look like if we designed it from scratch in today's sociotechnological environment, unconstrained by existing international treaties and other law and practice. $^{4}$

There is an urgent need for this thought experiment. Even as we write, the international framework is becoming incrementally more constraining. International treaties in intellectual property are increasingly framed not in statements of general principles, but as an ever more detailed reflection of domestic legislation. This is particularly notable in recent (albeit, at the time of publication, stalled) trade negotiations, particularly for the Trans-Pacific Partnership (TPP) and the Transatlantic Trade and Investment Partnership (TTIP). There are serious questions about the appropriateness of locking in specific details of the current system. We live in a fast-changing social and technological environment. Only 20 years ago few people were even

the World Trade Organization, opened for signature 15 April 1994, 1867 UNTS 3 (entered into force 1 January 1995), annex IC ('Agreement on Trade-Related Aspects of Intellectual Property Rights'), respectively): see $<$ www.copyrightcode.eu $>$.

2 See generally Mark A Lemley, 'IP in a world without scarcity' (2015) 90 NYU Law Review 460.

3 Mark A Lemley, 'Faith-Based Intellectual Property' (2015) 62 UCLA Law Review 1328.

4 By treaties, we are referring generally to supranational legal instruments, including the various EU Directives. When we talk about 'copyright', we include the civil law notion of author's rights (droit d'auteur or urheberrecht). 
online. Now, even if large swathes of the world's population still lack that opportunity, many of us routinely carry the means of accessing most of the world's knowledge and culture with us in our pockets. If we don't know what technology will look like 20 years from now, or how society will have changed, how can we possibly know what system of regulation we will need? There is also a risk that, if we view the possibilities for systemic change wearing the blinkers of existing international constraints, we'll miss identifying better ways of achieving our aims. Incremental thinking that merely proposes small changes at the margins is not, in and of itself, sufficient.

And so, drawing inspiration from Jessica Litman, ${ }^{5}$ we invite you to join in our thought experiment: if we could draw up a new copyright law, from a blank slate, ignoring current international legal constraints, what might it look like? As a starting point, any attempt at such fundamental rethinking needs at least some guiding principles or goals. We turn therefore to our guiding principle - the aim of furthering the public interest.

\section{The 'public interest' (please don't stop reading)}

The organising principle we have used as our springboard is that copyright should serve the public interest. But this does not necessarily mean what you think it means - assuming you think it has a meaning at all.

Your first instinct might be to dismiss the concept of the public interest as 'vacuous, deceptive and generally useless' . ${ }^{6}$ As a concept, the public interest may have been around for thousands of years, but generations of philosophers, economists, political scientists, lawyers and regulators have made little progress in determining precisely what we mean by it, ${ }^{7}$ leaving many sceptical about (or even vexed by)

5 In 2001, Jessica Litman asked readers to engage in a thought experiment: imagining that they were the US public's copyright lawyer asked to advise whether the public should agree to the deal; Litman, above n 1, 70.

6 Virginia Held, The Public Interest and Individual Interests (Basic Books, 1970) 1.

7 As a result it is often left 'totally undefined': Robert A Dahl and Charles E Lindblom, Politics, Economics, and Welfare: Planning and Politico-Economic Systems Resolved Into Basic Social Processes (Harper \& Row, 1963) 501. 
its usage. Sorauf nominated it to head a list of ambiguous phrases that would 'never be missed', ${ }^{8}$ complaining that, not only was there no current or emerging consensus about its meaning, but scholars don't even agree 'about what they are trying to define: a goal, a process, or a myth'. ${ }^{9}$ That lack of substantive content means that:

any detailed inquiry about its exact meaning plunges the inquiry into a welter of platitudes, generalities, and philosophic arguments. It soon becomes apparent that no general agreement exists about whether the term has any meaning at all, or, if it has, what the meaning is, which specific actions are in the public interest and which are not, and how to distinguish between them. ${ }^{10}$

The term's amorphousness also renders it susceptible to hijack; 'hopelessly vulnerable to annexation or colonization by those who exercise power in society'. ${ }^{11} \mathrm{Dahl}$ and Lindblom find that '[o]ften enough a precise examination would show that it can mean nothing more than whatever happens to be the speaker's own view as to a desirable public policy'. ${ }^{12}$ As Flathman laments, 'the misuse of the concept (and its ancestors) is as old as politics'. ${ }^{13}$ Alexander further captures the slipperiness of the concept:

The notion of 'public interest' is not a single or unified concept its content will vary depending upon who is considered to make up 'the public' and who is articulating its interests. At times different interests may come into conflict, and at other times they may be complementary. ${ }^{14}$

8 Frank Sorauf, 'The Conceptual Muddle' in Carl J Friedrich (ed), Nomos V: The Public Interest (Atherton Press, 1962) 190. See also Glendon Schubert, The Public Interest: A Critique of the Theory of a Political Concept (Free Press, 1960) 224, arguing that the concept 'makes no operational sense, notwithstanding the efforts of a generation of capable scholars'.

9 Sorauf, above n 8, 186; see also Mike Feintuck, 'The Public Interest' in Regulation (Oxford University Press, 2004) 3, noting that anything more than the most superficial examination of the term 'the public interest' reveals enormous difficulties in defining this 'deceptively familiar concept.'

10 Anthony Downs, 'The public interest: Its meaning in a democracy' (Spring 1962) 29 Social Research 1.

11 Feintuck, above n 9, 33.

12 Dahl and Lindblom, above n 7, 501. See also Richard C Box, 'Redescribing the Public Interest' (2007) 44(4) The Social Science Journal 585, 585-586, arguing that its uncertain meaning 'allows it to be used to justify individual or group preferences or undemocratic use of public power'.

13 Richard E Flathman, The Public Interest: An Essay Concerning the Normative Discourse of Politics (John Wiley \& Sons, 1966) 9.

14 Isabella Alexander, Copyright Law and the Public Interest in the Nineteenth Century (Hart Publishing, 2010) 16. 
Perhaps more encouragingly, Alexander describes the concept's opacity as both strength and weakness: 'strength because the simpler a rhetorical appeal can be made, the more likely it will resonate with its audience; weakness because it can be used as a cloak for private interests and thereby discredited ${ }^{\prime}{ }^{15}$

These shortcomings are well and truly evident when people debate copyright. In this context, the public interest is sometimes treated as synonymous with the current law as enacted - perhaps on the assumption that whatever the legislature has decided to do is, by definition, 'in the public interest' ${ }^{\prime}{ }^{16}$ But more often, copyright's various constituencies will give the concept of the public interest in copyright a meaning consistent with their own visions of copyright, or using it to promote specific policy or law reform goals or a particular outcome in a dispute.

For example, the public interest in copyright is sometimes used synonymously with the interests of those protected by copyright namely, authors and owners. That is how the Berne Convention appears to have treated concepts of the 'public interest' and 'public good'; so too did US Copyright Register Maria Pallante when she described authors' interests being 'not a counterweight to the public interest but $\ldots$ at the very centre of the equation' ${ }^{17}$

On the other hand, in recent times the 'public interest' has also been increasingly used as a proxy for 'user' (or even 'consumer') interests. This leads to its being invoked 'in favour of free and unfettered access by the public to copyright works combined with the means of copying them for personal use'. ${ }^{18}$ Along similar lines, the public interest is sometimes used as the counterweight to author interests or, in other words, the interests of everyone but authors and owners. For example, the preamble to the WIPO Copyright Treaty emphasises 'the need to

\footnotetext{
15 Ibid.

16 Sherwin Siy, 'Two Halves of the Copyright Bargain: Defining the Public Interest in Copyright' (2012-2013) 31(3) Cardozo Arts \& Entertainment Law Journal 683, 684 citing eBay Inc $v$ MercExchange LLC, 547 US 388, 391 (2006).

17 Pallante's comments are in her testimony to Congress at 3: Maria A Pallante Statement to the Register of Copyrights of the United States Subcommittee on Courts, Intellectual Property and the Internet Committee on the Judiciary, United States House of Representatives $113^{\text {th }}$ Congress, $1^{\text {st }}$ Session, 'The Register's Call for Updates to U.S. Copyright Law' <web.archive. org/web/20130418013229/http://judiciary.house.gov/hearings/113th/03202013/Pallante\% 20 032013.pdf>.

18 Gillian Davies, Copyright and the Public Interest (Sweet \& Maxwell, $2^{\text {nd }}$ ed, 2002) 7.
} 
maintain a balance between the rights of authors and the larger public interest, particularly education, research and access to information' ${ }^{19}$ Davies has suggested that 'from the inception of the copyright system, there has been a built-in tension between the interests of the author on the one hand and those of the public on the other ${ }^{\prime 20}$ The US Copyright Principles Project expresses a richer conception of the public interest but still places it in opposition to the interests of copyright owners:

A well-functioning copyright law carefully balances the interests of the public in access to expressive works and the sound advancement of knowledge and technology, on the one hand, with the interests of copyright owners in being compensated for uses of their works and deterring infringers from making market-harmful appropriations of their works, on the other. ${ }^{21}$

There are obvious problems with conflating 'the public interest' with one specific interest group or another. Such conceptions will rarely convince others in the context of the perennial copyright debate. As Alexander argues, it is simply unrealistic to treat the public interest as synonymous with ever-stronger intellectual property (IP) rights, or to treat every other interest (including access to works for both the broader public and second generation authors) as being somehow outside the copyright system. Equally, however, taking authors out of the equation entirely takes the heart out of copyright law, and fails to recognise the public's interest in the creation of a diversity of cultural material.

We can avoid these problems by recognising that the public interest must encompass a range of goals. Thus Barbara Ringer, a former Register of the US Copyright Office, once defined the public interest as 'the aggregate of the fundamental goals that the society seeks to achieve for all of its members - not for a majority of its members or for any large and powerful group, but for all of the people within

19 World Intellectual Property Organisation Copyright Treaty, opened for signature 20 December 1996, 36 ILM 65 (entered into force 6 March 2002) ('WIPO Copyright Treaty').

20 Davies, above n 18, 235.

21 See also G Dworkin, 'Copyright, The Public Interest and Freedom of Speech: A UK Copyright Lawyer's Perspective' in J Griffiths and U Suthersanen (eds), Copyright and Free Speech: Comparative and International Analysis (Oxford University Press, 2005) 154, stating that '[c]opyright and the public interest are inextricably linked. All copyright systems seek to strike a balance between the rights of the owner and the public interest'. 
the society'. ${ }^{22}$ The fundamental societal goals commonly described as constituting the public interest in copyright include the promotion of creativity, ${ }^{23}$ learning and progress, ${ }^{24}$ the widest possible creation, dissemination and access to works ${ }^{25}$ (including space to 'produce new works by building on the ideas and information contained in the works of others' $){ }^{26}$ freedom of expression, ${ }^{27}$ the preservation of culture ${ }^{28}$ and a robust public domain. ${ }^{29}$ Alternatively, descending below grand social goals to focus on something more personal and specific, we might argue, with Ginsburg among many others, ${ }^{30}$ that ' $[t]$ he public interest comprises the goals and aspirations of authors and users, of publishers and educators, and so forth'. ${ }^{31}$

This, however, takes us back to platitudes; such general aspirations provide no real guidelines for deciding what a copyright law in the public interest would look like.

22 Barbara Ringer, 'Authors' rights in the electronic age: Beyond the Copyright Act of 1976' (1981) 1(1) Loyola Entertainment Law Journal 2 (first emphasis added).

23 Neil Netanel, 'Why has Copyright Expanded? Analysis and Critique' in F Macmillan (ed), New Directions in Copyright Law, Volume 6 (Edward Elgar, 2008) 4; 'The Washington Declaration on Intellectual Property and the Public Interest' (2013) 28(1) American University International Law Review 19, 21.

24 See e.g. Davies, above n 18, 12; Preamble to WIPO Copyright Treaty emphasising 'the need to maintain a balance between the rights of authors and the larger public interest, particularly education, research and access to information'; Sam Ricketson, 'The Copyright Term' (1992) 23(6) International Review of Intellectual Property \& Competition Law 753, 755.

25 See e.g. Davies, above n 18, 7, 16; 'Intellectual Property and Innovation', CMnd 9712, HMSO, 1986 (UK government white paper from 1986) 35, [4].

26 CCH Canadian $v$ Law Society of Upper Canada [2004] 1 SCR 339 [23].

27 Ashdown $v$ Telegraph Group Ltd [2001] EWCA Civ 1142, in which the UK Court of Appeal suggested that the UK's fair dealing exceptions 'will normally afford the Court all the scope that it needs properly to reflect the public interest in freedom of expression and, in particular, the freedom of the press', at [66]. See also [71], explaining how essential it is to remember that 'considerations of public interest are paramount' and thus not to apply tests inflexibly. Also 'The Washington Declaration on Intellectual Property and the Public Interest' (2012) 28(1) American University International Law Review 19, 25; Ricketson, above n 24, 753, 755.

28 See e.g. Australian Law Reform Commission, Copyright and the Digital Economy Final Report, Report No 122 (2013) 278; Laura N Gasaway, 'America's Cultural Record: A Thing of the Past?' (2003) 40(3) Houston Law Review 643-671.

29 'The Washington Declaration on Intellectual Property and the Public Interest', above n 27, $19,21$.

30 Caron also describes the rights of authors and the public as being 'indissociable in nature': Christophe Caron, 'Abuse of Rights and Author's Rights' (1998) 176 Revue Internationale du Droit d'Auteur, 2, 54.

31 Jane C Ginsburg, 'Authors and Users in Copyright' (1997) 45(1) Journal of the Copyright Society of the USA 1, 4. 


\section{We still need this concept}

If leading thinkers have trouble defining the public interest, and if the term can be hijacked, why shouldn't it simply be abandoned? The answer is because it captures something important about the goals of public policy, and because abandoning the concept simply leaves a void that something else must fill:

The problems associated with 'public interest' are among the crucial problems of politics. Determining justifiable governmental policy in the face of conflict and diversity is central to the political order; it is a problem which is never solved in any final sense but which we are constantly trying to solve. The much-discussed difficulties with the concept are difficulties with morals and politics. We are free to abandon the concept, but if we do so we will simply have to wrestle with the problems under some other heading. ${ }^{32}$

Held agrees, suggesting that concepts such as the public interest are 'indispensable' in enabling evaluations of government decisions. ${ }^{33}$ Thus, while we don't exactly know what the public interest means, and will debate its content forever, we have a keen intuition that it is important - hence former US Supreme Court Justice Felix Frankfurter's description of it as a 'vague, impalpable but all-controlling consideration'.$^{34}$ We need the concept of the public interest because its absence would leave lacunae in policy development and evaluation. As Colm observes, 'it is difficult to imagine that politicians, statesmen, judges, and officials concerned with the formulation of government policies could do without this concept' ${ }^{\prime}{ }^{35}$

Fundamentally, the concept of the public interest stands for something central to our democratic system: the idea that 'we' are not just a welter of self-interested individuals out to further our own specific interests regardless of the impact on others, but rather, that we make up a society, in which guise we can have a shared set of interests. It also suggests that, on occasion, furtherance of those shared interests can

\footnotetext{
32 Flathman, above n 13, 13.

33 Held, above n 6, 9-10.

34 Quoted in Gerhard Colm, 'The Public Interest: Essential Key to Public Policy' in Carl J Friedrich (ed), Nomos V: The Public Interest (Atherton Press, 1962) 115.

35 Ibid 127.
} 
and should take precedence over individual or group self-interest. ${ }^{36}$ Thus, although 'its fuzziness makes it awkward as a practical guide to daily affairs', ${ }^{37}$ the concept invokes considerations that cannot be ignored. ${ }^{38}$

For our purposes in this book, too, the other most common trope in copyright policy discussions - the concept of 'balancing interests' is deeply unsatisfactory. ${ }^{39}$ 'Balance' helps define what is politically feasible, but not what is socially desirable. ${ }^{40}$ A policy change is seen as being 'unbalanced' if it favours one existing stakeholder more than another, regardless of its objective merits. Thus the notion of 'balance' favours existing ways of doing things, business models and interests. We want to move past that constraint to consider what good policy would actually look like, regardless of how it might impact the slices of those who currently divide up the pie.

\section{Methods for giving content to 'the public interest': The tools of philosophy}

If we want to reimagine copyright to better further the public interest, we need to be able to give that concept some content. Thankfully, we are not the first to attempt to do so. Generations of social and political philosophers have already wrestled with this problem, and they have produced some tools that can help.

\footnotetext{
36 Charles J Fox and Hugh Theodore Miller, Postmodern Public Administration: Toward Discourse (Sage Publications, 1995) 123-124.

37 Box, above n 12, 585, 586.

38 For example, Feintuck, above n 9, 3, 25; Held, above n 6, vii; Downs, above n 10, 1-2.

39 See Story's review of the literature, which found references to various copyright systems providing "“a just balance", "a good balance", "a weak balance", "the proper balance", "the appropriate balance", "an unfair balance", and an "equitable balance"'; “c]ommentators on copyright often worry that some legal change has "tilted the balance" or "upset [the balance] unnecessarily" and that we need to "redress the balance."' Alan Story, 'Balanced Copyright': Not a Magic Solving Word (27 February 2012) Intellectual Property Watch <www.ip-watch.org/2012/02 $/ 27 / \%$ E2 $\% 80 \% 98$ balanced $\%$ E2\%80\%99-copyright-not-a-magic-solving-word/>. See also Carys Craig, reminding us that "the idea of "balancing" competing interests is no more than a metaphor itself, albeit one that is a pervasive and persuasive presence in modern legal discourse': Carys J Craig, 'The Evolution of Originality in Canadian Copyright Law: Authorship, Reward and the Public Interest' (2005) 2(2) University of Ottawa Law \& Technology Journal 425, 441.

40 Lok Sang Ho, Public Policy and the Public Interest (Routledge, 2012).
} 
Held's typology divides public interest conceptions in general legal and political philosophy into three main categories: 'preponderance theories', 'common interest theories', and 'unitary theories'. ${ }^{41}$ 'Interest' can itself have different meanings, ${ }^{42}$ but here we adopt Held's approach of limiting ourselves to interests 'in something being done, or enacted, or brought about, or maintained'.$^{43}$

Preponderance theories suggest that the public interest 'cannot be in conflict with a preponderance or sum of individual interests' ${ }^{4}{ }^{4}$ Epitomised by the work of Hobbes, Hume and Bentham, such aggregationist theories suggest that 'something might be in the public interest where it's not in an individual's interest, as long as it's in the interests of sufficient individuals' ${ }^{45}$ Davies seems to have adopted a preponderance conception in Copyright and the Public Interest:

Whether a particular act is 'in the public interest' is probably not subject to any objective tests. Inherent in the noble motive of the public good is the notion that, in certain circumstances, the needs of the majority override those of the individual, and that the citizen should relinquish any thoughts of self-interest in favour of the common good of society as a whole. ${ }^{46}$

One unanswered and vexing question concerns how this preponderance is to be judged. Is it by simple majority of numbers, or weighted by political strength? Is it 'to be judged in empirical or behavioral terms, as a higher degree of force, or a greater weight of actual opinion, or a superior group strength' $?^{47}$ And of course there is the obvious problem: how to factor in minority interests. ${ }^{48}$

\footnotetext{
41 Held, above n 6, 42-46. Alternative typologies have also been established by a number of other scholars. See e.g. EC Banfield, 'Note on Conceptual Scheme' in M Meyerson and EC Banfield, Politics, Planning and the Public Interest (Free Press, 1955); Schubert, above n 8; CE Cochran 'Political science and the public interest' (1974) 36(2) Journal of Politics 327; Wayne AR Leys and Charner Marquis Perry, 'Philosophy and the Public Interest: A document' (Paper presented at the Symposium of the Western Division of the American Philosophical Association, University of Wisconsin, 1 May 1959).

42 See e.g. Flathman, above n 13, 14-31.

43 Held, above n 6, 19.

44 Ibid 43.

45 Ibid (emphasis added).

46 Davies, above n 18, 4.

47 Held, above n 6, 83.

48 Feintuck suggests a 'counter majoritarian' response would be needed: Feintuck, above n 9 , 12 (internal note omitted).
} 
Common interest theories avoid these difficulties by requiring unanimity. That is, they suggest that something will only be in the public interest where it is in the interests of all members of a polity. ${ }^{49}$ As Barry observes, interests common to all members of society are rare, ${ }^{50}$ but do exist: operational monetary systems, sustainable access to breathable air and drinkable water, and community firefighting facilities are all in the common interest. Rousseau, a leading proponent of this view, rejected preponderance theories on the grounds that simply following the preponderance of opinion might mean yielding to force, acting out of necessity rather than inclination. ${ }^{51}$ Common interest theories suggest that where a policy triggers conflict between individual interests it cannot be in the public interest. But given the near impossibility of persuading all voters to favour a given policy, common interest theories are unlikely to provide a mechanism for effective decision-making involving large groups. Common interest theories seem even less likely to be a helpful guide to copyright policymaking, given the contentiousness arising from its multitude of often competing private interests.

Preponderance and common interest theories are sometimes described as process theories, because they provide a process for determining where the public interest lies without purporting to give it normative content. This has led to criticism for lack of usefulness. For example, in the context of preponderance theories, Held has noted that:

to assert that ' $x$ is in the interests of a preponderance of individuals' implies only that ' $x$ is in the interests of a preponderance of individuals.' ... [I]f we want to know whether a given $x$ is in the public interest, we want to know something else than the empirical fact that it is in the interests of a preponderance of individuals, although being in the interests of a preponderance of individuals may well be among the possible good reasons for believing that such an $x$ is in the public interest. ${ }^{52}$

\footnotetext{
49 Held, above n 6, 44.

50 BM Barry, 'The Use and Abuse of the Public Interest' in Carl J Friedrich (ed), Nomos V: The Public Interest (Atherton Press, 1962) 199.

51 Held, above n 6, 100, citing Jean Jacques Rousseau, The Social Contract: Book 1 (Charles Frankel, New York, 1947) ch 3, 8-9.

52 Held, above n 6, 84 .
} 
In reality however, process theories must involve some normative content being given to the concept of the public interest. That is because a determination as to whether a given policy is in the interests of either a majority or all of a polity cannot be made without identifying where those interests actually lie. For example, whenever it is argued that a given policy is in the public interest because it is in everybody's interest, a normative judgment is being made that is in fact that case - that it is indeed desirable to have a robust national defence force or independent judiciary or stable currency or whatever the policy might be. Thus, before process conceptions of the public interest can be applied there must at least be some implicit normative basis for deciding that certain things are desirable while others are not. Sometimes this is clear-cut; for example, most people would argue that a policy to criminalise murder is in all or most individuals' interests. When it comes to copyright policy, however, it can be much more difficult to determine where all or a preponderance of individuals' interests lie. Are they better served by policies that facilitate access but risk certain kinds of new content being underproduced, or those that incentivise the creation of more or particular kinds of content but result in overall less use?

The third category in Held's typology can be described as 'unitary' theories. In this conception, which can be traced to the work of Plato and Aristotle, and later Hegel and Marx, if something is in the public interest as a matter of 'valid' judgment, it must also be in each individual's interest. Equally, if something is not in the interest of an individual as a matter of such judgment, then it cannot be in the public interest either. ${ }^{53}$ Unlike the process conceptions, unitary theories give explicit normative content to the concept of the public interest. Validity or justifiability are conferred by the universal moral order, and whether something is in the public interest is determined on that basis. ${ }^{54}$ The obvious difficulty with such a formulation is in reaching agreement on where this 'objective good' actually lies. Plato and Aristotle differed significantly on this question, ${ }^{55}$ and the subsequent 2,000 years have not brought the world any closer to moral unanimity. There is widespread disagreement about whether the moral content of the public interest aligns with the interests of the state (as posits the 
Hegelian view), the Church, the society or some other benchmark. ${ }^{56}$ Also problematic is the refusal of unitary theories to permit the existence of any justifiable conflict between the public interest and individual interests. ${ }^{57}$ That is, any individual's disagreement with the morally valid 'public interest' would itself, by definition, be invalid. While moral validity may sometimes be clear, in the case of copyright policy the wide range of genuinely held yet contradictory views as to what it is seeking to achieve make it difficult to identify any moral 'right' without dismissing core philosophical and cultural concerns. For example, for Tang, writing on the public interest in copyright in China, a key consideration is whether the act 'stimulates a socialist spirit and values'. ${ }^{58}$ That this is not a consideration that would necessarily animate the concept elsewhere hints at the difficulty of defining a morally valid 'public interest' in copyright. The fundamental debates over instrumentalist versus naturalist copyright traditions, discussed below, make it more difficult still.

More recently, Ho has put forward a method for determining the public interest using a familiar ex ante perspective:

The public interest is the interest of 'the representative individual' an imaginary person who forgot his identity and who imagined that he had equal chance of being anyone in society. By pondering policy options using this ex ante perspective impartially, the most preferred option is the one that is deemed to maximize the public interest. With the public interest defined this way, policy decisions should be made on the basis of comparing benefits in terms of enhancement of the public interest on the one hand, and costs on the other hand..$^{59}$

As well as having roots in work by Mill and Harsanyi, this ex ante framework evokes the Rawlsian 'invisible veil', which suggests that the principles of justice must be determined by individuals in a 'hypothetical situation of equal liberty':

\footnotetext{
56 Ibid 154-156.

57 Ibid 156-158.

58 Guan H Tang, Copyright and the Public Interest in China (Edward Elgar, 2011) 122.

59 Ho, above $\mathrm{n} 40,8$.
} 
Among the essential features of this situation is that no one knows his place in society, his class position or social status, nor does any one know his fortune in the distribution of natural assets and abilities, his intelligence, strength, and the like. I shall even assume that the parties do not know their conceptions of the good or their special psychological propensities. The principles of justice are chosen behind a veil of ignorance. This ensures that no one is advantaged or disadvantaged in the choice of principles by the outcome of natural chance or the contingency of social circumstances. Since all are similarly situated and no one is able to design principles to favor his particular condition, the principles of justice are the result of a fair agreement or bargain. ${ }^{60}$

Of course, analyses carried out via Ho's framework or under cover of the Rawlsian veil are unlikely to be truly representative: they will always be shaped to some extent by the attitudes of the wielders. If these devices are predominantly employed by white, liberal, middle-class individuals, the results will disproportionately reflect white, liberal, middle-class world views. What the representative individual framework is very effective in stripping away, however, in common with its predecessors in the work of Mill, Harsanyi and Rawls, is privilege. This attribute is essential given the need to reflect the full range of voices and interests impacted by copyright policies. The representative individual might not be truly and universally representative, but, by stripping away privilege and its associated benefits, such as political strength, the framework at least enables fuller consideration to be given to the breadth of individual and group interests at play. Vested interests tend to dominate and distort policy thinking in copyright. ${ }^{61}$ In thinking about what the law should be, or would be if we designed it today, it is clearly vital to divorce ourselves from such positions. If we want to think outside existing frameworks, we need to think in terms of policy goals rather than the tools or institutional or market structures we currently use to achieve those goals. This is of course easier said than done, but one of the main

60 John Rawls, A Theory of Justice (Belknap Press, 2005) 11-12 (emphasis added).

61 As Litman has observed, '[a]ny given copyright law will be more hospitable to some sorts of technological change than to others. Interests who find themselves, usually more by reason of accident than design, in a favorable legal position will naturally resist proposals to tinker with it'. Litman, above $n$ 1, 36. 
attractions of Ho's conception is that it does help to free the mind from self-interest and traditional ways of doing things, and ensure representation of a broader range of interests.

Like the preponderance, common interest and unitary conceptions of the public interest already identified, Ho's 'representative individual' approach requires some normative judgments to be made before the tool can be of any use. The representative individual would be unable to determine the best policy unless she knows broadly what she wants it to achieve. Before she designs a copyright policy, she needs to know whether she is trying to design a content creation and cultural/knowledge advancement copyright policy, a copyright policy for the protection and promotion of artist's inherent and inalienable interests in their creations, or something else altogether. To the extent that she has a combination of aims, she needs to understand their interrelationships with one another, and, to the extent that they're inconsistent, have an idea about how they should be subordinated to one another.

Although Ho is an economist, we do not read his formulation as limiting the representative individual's considerations to the purely economic. This would be a shortcoming indeed; conceptions of the public interest dominated by a focus on allocative efficiencies have been justly criticised for being too narrow. ${ }^{62}$ Instead, the 'representative individual' could take into account any relevant moral, ethical or philosophical beliefs and considerations in determining whether any given policy is in the public interest. This is an essential feature when considering copyright policy, which is nowhere purely a creature of instrumentalism. The representative individual ought also be sufficiently generous and wise to include the interests of future generations in forming her view, something that existing processbased conceptions of the public interest do not necessarily take into account, ${ }^{63}$ but which is vital given the impact of copyright policies on future generations.

62 See e.g. Feintuck, above n 9, 13-21; M Blitz, 'Public Interest' in NJ Smelser, James Wright and PB Baltes (eds), International Encyclopedia of the Social \& Behavioural Sciences (Pergamon, June 2014) 12546. ('There are, however, limits to this perspective. They are evident in the narrowness of the economic view of the public when it is compared to other notions of what is potentially common in common goods.')

63 See e.g. Feintuck, above n 9, 13. 
In summary, the above-described conceptions give guidance about various ways in which a copyright law that is actually in the public interest might be shaped:

1. by formulating it to be consistent with the preponderance of individual interests within a polity (which requires identifying where those interests lie, as well as how that preponderance is to be determined - by weight of numbers, political strength or some other factor);

2. by formulating it to be consistent with everyone's individual interests, or at least, as unanimously agreed by members of the polity (which requires the making of that same determination);

3. by formulating it to be 'valid', that is, morally justified (which assumes that moral validity is capable of determination - and of course, that determination of what is 'right' must depend on what is intended to be achieved);

4. by formulating it using a constructed, impartial ex ante perspective to determine the policy that maximises the public interest (which also requires determination of what the policy is intended to achieve).

\section{What do we want copyright law to achieve?}

The above analysis provides a vital lesson: that, regardless of which conception is adopted, it is impossible to argue sensibly that any copyright policy is in the public interest without explicitly identifying what it seeks to achieve. That sounds obvious, and in fields where policy aims are clear, presents few problems. Here, however, it leads us directly into what Alexander describes as copyright's 'heart of darkness: the justification for its existence' ${ }^{64}$

Historical rationales for the grant of copyright can be broadly clustered into 'naturalist' and 'instrumentalist' theories. Instrumentalist approaches justify the grant of copyright as a way of achieving certain social and economic aims, such as the dissemination of knowledge and culture. In this view, copyright laws are justified only to the extent they further public interest considerations. By contrast, naturalist

64 Alexander, above n 14, 3. 
approaches assume that authors have expansive rights over their creative outputs as of right. Those rights are most commonly explained as springing from the output being brought about by the author's labour (the Lockean approach) or because it is a materialisation of her personality (per Kant and Hegel). In these conceptions, 'the author acquires a property right in his work by virtue of the mere act of creation. This has the corollary that nothing is left to the law apart from formally recognising what is already inherent in the "very nature of things"'". ${ }^{5}$

At their extremes, the two approaches are fundamentally inconsistent. Instrumentalist justifications have public interest considerations squarely at the fore, while in naturalism the public's role is secondary. ${ }^{66}$ One treats authors' rights as a means to an end, and the other as an end in and of themselves.

The reality is that considerations traceable to both rationales can be found alongside one another within both international treaties and domestic laws. ${ }^{67}$ Countries operating within ostensibly instrumentalist traditions have often adopted policies that are clearly motivated by naturalist considerations, and vice versa.$^{68}$ For example, the US Constitution limits Congressional power to grant intellectual property rights to where it 'promote[s] the progress of science and the useful arts $^{\prime}{ }^{69}$ But despite that express utilitarian focus, such considerations

65 Martin Senftleben, Copyright, Limitations and the Three Step Test (Kluwer Law International, 2004) 6.

66 Alexander, above n 14, 3; also Davies, above n 18, 171; Ricketson, above n 24, 753, 755. This perhaps explains why the copyright discourse so often conceptualises the 'public interest' in opposition to authors' interests.

67 See e.g Senftleben, above n 65, especially at 6-10; Alain Strowel, Droit d'auteur et copyright, Divergences et Convergences (Bruylant, 1993); Davies, above n 18, 348-351; Jerome Reichman, 'Duration of Copyright and the Limits of Cultural Policy' (1996) 14(3) Cardozo Arts \& Entertainment 625, 643-644, Ricketson, above n 24, 753, 755.

68 As Senftleben argues, it's inaccurate to conceive of the two traditions, European and Anglo-American, as incompatible and separate. Instead, 'the two traditions of copyright law can be described as mixtures of a shared set of basic ideas derived from natural law theory and utilitarian notions alike': Senftleben, above n 65, 10.

69 United States Constitution Art IV $\S 8$. 
are not always given primacy. ${ }^{70}$ Similarly, the European Copyright Directive, created in the heartland of continental naturalism, emphasises instrumentalist aims like 'foster[ing] substantial investment in creativity and innovation', which would 'lead in turn to growth and increased competitiveness of European industry', in order to 'safeguard employment and encourage new job creation'.$^{71}$ Multilateral treaties, too, contain elements of both: property rights accompanied by explicit mention of authors' moral rights and a term tied to the life of the author. It is not unusual for a particular policy to be explainable only through a combination of instrumentalist and naturalist approaches. ${ }^{72}$

This is not surprising. Extreme manifestations of the two dominant philosophical approaches are unattractive and unrealistic. A purely economic approach in which we aim for a legal system that gives the absolute minimum reward to creators to ensure an adequate level of culture and knowledge is just as difficult to swallow as an extreme conception of author's rights in which creators get total control and dominion over their creative products forever. The juxtaposition of rationales, uneasy as it may sometimes be, is inescapable.

Perhaps this is, ultimately, the argument for using, defining and defending the public interest as an organising principle for thinking about how we might reimagine copyright. Whatever conception of the public interest we use, at base, it is about recognising that we have an overall shared set of interests as a society beyond individual self-interest. In the copyright context, we have a shared interest in encouraging and supporting creativity; in recognising the rights and interests of creators, in a rich and accessible culture, and in technological and economic progress. We can and will differ on the

70 As Jaszi has observed, 'over the history of Anglo-American copyright, Romantic "authorship" has served the interests of publishers and other distributors surprisingly well': Peter Jaszi, 'On the Author effect: Contemporary Copyright and Collective Creativity' (1992) 10(2) Cardozo Arts \& Entertainment Law Journal 293, 298. Goldstein also notes that '[w]hile congressional committees will episodically invoke the utilitarian rhetoric of cost and benefit, the legislative record in fact reveals a regular expansion of copyright with little empirical inquiry into a particular measure's costs and benefits'; Paul Goldstein, Aspen Publishers Inc., Goldstein on Copyright, 1.13.2.

71 Directive 2001/29/EC of the European Parliament and of the Council of 22 May 2001 on the Harmonisation of Certain Aspects of Copyright and Related Rights in the Information Society [2001] L $167 / 10$, recital 4.

72 See e.g. Peter Drahos, A Philosophy of Intellectual Property (ANU Press, 2016) 96-97. 
details of how to get there, but, in common with Ginsburg, we would argue that the public interest in copyright comprises the goals and aspirations of authors and users, of publishers and educators, and so forth. ${ }^{73}$

But still, in using this concept, it is important to avoid the pitfalls recognised in the philosophical literature above. Having recognised that all too often 'the public interest' either stands instead for one stakeholder or another, or worse, is simply used with no meaning at all, it is beholden on anyone undertaking a reimagining of any aspect of copyright 'in the public interest' to be explicit about how they are conceiving the public interest; the specific goals they are trying to achieve, and why their proposals are a good way of achieving them.

\section{What could copyright law look like if we were not constrained by existing treaty obligations?}

This book draws together a set of sometimes provocative imaginings for a public interest-furthering copyright law freed of the constraints of existing frameworks. In the contributions that follow, we and our international colleagues explore what copyright should hope to achieve, and imagine ways in which copyright frameworks could be redesigned to further those aims. Since they come from lawyers, these proposals will look different than those that would be put forward by sociologists, psychologists, creators or any other group. However, they are informed by a rich mixture of experience within a wide variety of copyright traditions and philosophies, and though grounded in law, benefit from significant expertise across such diverse fields as technology, economics, philosophy and international trade. The topics covered in the book span issues relating to subsistence, scope and duration of rights, how systems might better facilitate the remuneration of creators, whether and how copyright systems should incorporate formalities, how to solve problems of orphan works, what role copyright might have as a tool for achieving distributive 
justice, and what enforcement mechanisms might look like in a world where the copyright's structural and institutional problems have been largely solved.

Sometimes the contributors fundamentally disagree. For example, the reader will find very different visions here of the role of copyright. De Beer imagines a copyright that is almost purely market facilitative, leaving other goals to be addressed elsewhere in the legal system. By contrast, Senftleben challenges the appropriateness of leaving so much to the market: copyright is often presented as being intended to serve the individual interests of creators, but the reality is that many creators (especially those identified as 'autonomous' in Bourdieu's sociological analysis) may never achieve a bargaining position that could allow them to effectively exploit their rights. Both Ncube and Geiger argue that copyright law itself must be framed more explicitly around social goals and dimensions. Ncube highlights the failure of existing market-based copyright systems to incentivise the production of works for economically disadvantaged language populations, arguing for the incorporation of distributive justice as a goal (something de Beer acknowledges is neglected by the market). Geiger argues for the centrality of copyright's role in enabling access to science and culture, through, for example, the recognition of explicit obligations for copyright holders and the recognition that users have rights.

Another area where our colleagues have disagreed relates to what should fall within the scope of the copyright system. In a chapter primarily dealing with subsistence, Reese argues for a relatively low threshold of creativity for protection, and puts a case that the legislature is the appropriate gatekeeper in deciding what forms of creativity warrant copyright protection, with categories as clearly expressed as possible (though technology neutral). Geiger, on the other hand, imagines a higher threshold for protection expressed as a standard rather than a rule: in which case judges might be the ones to decide whether given material is sufficiently creative to warrant protection, and granting it only if it will not unduly interfere with future creation nor cause unjustified harm to legitimate public interests such as cultural participation. 
In various places the contributions touch upon similar issues. For example, Gangjee's contribution draws upon his expertise in registration-based trademark systems to flesh out how and why formalities could also help copyright. Giblin's chapter argues that we ought to disaggregate copyright's various goals in order to consider how they might best be achieved, and proposes an approach to duration that would not simply involve tinkering with term length, but would also need to integrate appropriate formalities (and compulsory licences and exceptions as well). Both Gangjee and Giblin suggest a kind of 'phased' copyright, with different rights (and obligations) at different points in the duration of copyright.

The importance of exceptions is addressed in a number of other chapters too. Ncube situates them as being essential in helping to rectify the failure of the market to produce a socially optimal amount of creative and informational works for neglected populations. Geiger and Senftleben both argue that some exceptions should be elevated to the status of user rights, with Geiger arguing that it is necessary to further copyright's essential access goals and Senftleben seeing certain rights of use as an essential part of the author's right to create. However, we made a deliberate choice not to incorporate a chapter focusing exclusively on exceptions. Though that is where the debate about where the public interest in copyright has long been centred, our intention is to highlight the wider public interest in other aspects of copyright. As Craig has persuasively argued, the public has interests vitally at stake in all aspects of drafting copyright law, and leaving public interest considerations until exceptions analyses - until a person has perhaps already been branded a free-rider and prima facie infringer - might well be leaving it too late. ${ }^{74}$

Each contribution adopts the unifying principle of the public interest, but here too there is rich divergence. Ncube and Reese adopt preponderance conceptions, defining the 'preponderance of interests' as one determined by sheer weight of numbers, rather than by political strength. Giblin takes Ho's representative individual and explores how that framework might change the way we think about duration policy. Weatherall adapts the representative individual approach in order to assess the public interest in copyright enforcement. Her chapter puts 
the reader in the shoes of a public regulator tasked with ensuring appropriate enforcement of copyright and considers the tools and approaches such a regulator would take in order to promote the broader societal interest in copyright. Geiger argues that there is in fact a common interest in copyright - an interest shared by society at large. The contribution from Senftleben proceeds on the assumption that it is necessary to first identify the interests of authors in order to meaningfully develop a public interest-furthering copyright; Gangjee too sets about identifying a series of specific public goals that formalities can either promote or harm. The assumption underlying de Beer's chapter is that the proper functioning of the capitalist market economy is itself in the public interest, with additional nuance coming from his recognition that further mechanisms can be necessary to mitigate the potential distributive injustices of the free market.

At other times there is a convergence of goals or ideas (or at least common themes). A number of contributors, including Ncube, Giblin and Weatherall, emphasise the importance of serving the interests of individual creators, although this is most explicitly at the fore in Senftleben's detailed exploration of the question - what do authors really want? Another common theme is the importance of access, albeit from different directions. Ncube highlights the dearth of genuine access to literature in neglected languages. Weatherall imagines tying at least the use of public resources in enforcement to access, raising doubts about whether strong rights of enforcement ought to be available to right holders who have not made their creations accessible, at a reasonable price. Geiger is concerned with something similar, arguing that copyright should come with a positive duty to disseminate.

We welcome all of this contestation. The aim in this collection is not to attempt to compile a new proposed Copyright Act, or one single, coherent whole, but to present some alternative visions and some specific proposals and ideas across the full scope of the copyright system. The range of ideas here should encourage us to remove our blinkers, and to start thinking through broader possibilities for achieving copyright's aims.

There is, however, one thing that all of these chapters have very much in common. Namely, not one of the proposals that the reader will find in these chapters could actually be implemented, at least in full, 
given the constraints of the existing international legal framework. And that is precisely why this thought experiment and these ideas are important, right now - every one of these chapters illustrates what possibilities we lose when existing rules become set in concrete. We'll have some more to say about that in the conclusion. 
This text is taken from What if we could reimagine copyright?, edited by Rebecca Giblin and Kimberlee Weatherall, published 2017 by ANU Press, The Australian National University, Canberra, Australia. 